\title{
CLINICAL STUDY OF END-ORGAN DAMAGE IN HYPERTENSIVE EMERGENCY
}

\author{
Hariom Gupta1, Shailendra Kumar Manjhvar2, Shivaji Thakare3, Manoj Indurkar ${ }^{4}$
}

${ }^{1}$ Associate Professor, Department of Medicine, Sanjay Gandhi Memorial Hospital and Shyam Shah Medical College, Rewa. ${ }^{2}$ Associate Professor, Department of Medicine, Sanjay Gandhi Memorial Hospital and Shyam Shah Medical College, Rewa. 3 Postgraduate Student, Department of Medicine, Sanjay Gandhi Memorial Hospital and Shyam Shah Medical College, Rewa. 4 Professor and HOD, Department of Medicine, Sanjay Gandhi Memorial Hospital and Shyam Shah Medical College, Rewa.

\section{ABSTRACT}

\section{BACKGROUND}

Hypertension is becoming an important public health problem worldwide. A recent report on the global burden of hypertension indicates that nearly 1 billion adults (more than a quarter of the world's population) had hypertension in 2000, and this is predicted to increase to 1.56 billion by 2025 .

This study makes an attempt to create awareness regarding various risk factors of hypertensive emergencies and their timely prevention, and hence decreasing mortality and morbidity associated with hypertensive emergencies.

\section{MATERIALS AND METHODS}

This study was done on patients with SBP $\geq 180 \mathrm{mmHg}$ or DBP $\geq 120 \mathrm{mmHg}$ admitted in Medicine Ward from March 2015 to May 2016 (200 patients). On admission, detailed history, complete clinical examination and necessary investigations like (blood and urine chemistry, ECG, CXR, fundoscopy, etc.) were done to know the end-organ damage.

\section{RESULTS}

In our study of 144 patients of hypertensive emergency, mean age for hypertensive emergency was $(63 \pm 10)$. We observed that $58 \%$ patients were male, $69 \%$ were sedentary, $67 \%$ were obese, $44 \%$ were dyslipidaemic, $47 \%$ were alcoholic and $43 \%$ were smoker. Retinopathy (66\%), Ischaemic stroke (23\%), Haemorrhagic stroke (16\%), Acute heart failure (18\%) and Acute coronary syndrome $(16 \%)$ were common end-organ damage in hypertensive emergencies.

\section{CONCLUSION}

Retinopathy and CNS manifestations were most commonly encountered end-organ damage in patients of hypertensive emergency. The early detection of multiple target organ damage and appropriate treatment are key determinants for reducing morbidity and mortality among patients of hypertensive emergency.

\section{KEYWORDS}

HC - Hypertensive Crisis, HE - Hypertensive Emergency, HU - Hypertensive Urgency, TIA - Transient Ischaemic Attack.

HOW TO CITE THIS ARTICLE: Gupta H, Manjhvar SK, Thakare S, et al. Clinical study of end-organ damage in hypertensive emergency. J. Evolution Med. Dent. Sci. 2017;6(13):1034-1036, DOI: 10.14260/Jemds/2017/221

\section{BACKGROUND}

Hypertension is becoming an important public health problem worldwide. A recent report on the global burden of hypertension indicates that nearly 1 billion adults (More than a quarter of the world's population) had hypertension in 2000 , and this is predicted to increase to 1.56 billion by 2025. ${ }^{1}$ Hypertension has been identified as one of the leading risk factors for mortality, killing nearly 9.4 million people every year globally and is ranked third as a cause of disability-adjusted life-years. ${ }^{2}$

A Hypertensive Crisis (HC) is classified as Hypertensive Emergency (HE) or Hypertensive Urgency (HU). Hypertensive emergency is characterised by a severe elevation of blood pressure (BP $\geq 180 / 120 \mathrm{mmHg}$ ) with evidence of progressive organ damage or target organ failure. Hypertensive urgency is defined as uncontrolled BP without failure or damage to the target organ. ${ }^{3}$

Financial or Other, Competing Interest: None.

Submission 06-01-2017, Peer Review 01-02-2017,

Acceptance 06-02-2017, Published 13-02-2017.

Corresponding Author:

Shivaji Thakare,

C/o. Dr. Hariom Gupta,

F-2, Doctors Colony, SS Medical College,

Rewa-486001.

E-mail:dr.shivaji21@gmail.com

DOI: $10.14260 /$ jemds $/ 2017 / 221$

\section{(c) $(1)$}

Hypertensive emergencies are common events in the emergency department and differ in their clinical patterns of presentation and still the prevalence and clinical picture of hypertensive emergencies in an emergency department are poorly known.

This study makes an attempt to create awareness regarding various risk factors of hypertensive emergencies and their timely prevention, and hence decreasing mortality and morbidity associated with hypertensive emergencies.

\section{MATERIALS AND METHODS}

Type of Study

Observational study.

\section{Duration of Study}

$1^{\text {st }}$ March 2015 till 31 ${ }^{\text {st }}$ May 2016.

\section{Place of Study}

Shyam Shah Medical College Associate S. G. M. H., Rewa.

\section{Sample Size}

This study was carried out on patients admitted to our hospital with hypertensive crisis in Medicine Wards from March 2015 to May 2016 (144 patients). 


\section{Inclusion Criteria}

1. All patients above 18 years of age.

2. Systolic blood pressure $>180 \mathrm{mmHg}$.

3. Diastolic blood pressure $>120 \mathrm{mmHg}$.

4. Both groups of patients, those with past history of hypertension and those without past history of hypertension.

\section{Exclusion Criteria}

1. Pregnancy.

2. Patients less than 18 yrs. of age.

3. Valvular heart diseases.

Hypertensive emergency in which the increase in blood pressure was associated with one or more of the following types of acute or ongoing end-organ damage: hypertensive encephalopathy; stroke (cerebral infarction, intracerebral haemorrhage, subarachnoid haemorrhage and transient ischaemic attack); acute pulmonary oedema, acute heart failure, acute myocardial infarction or unstable angina, progressive renal insufficiency and features suggestive of retinopathy.

All these conditions were diagnosed clinically and by diagnostic tests (blood and urine chemistry, fundus examination, ECG, roentgenogram and computed tomography) as appropriate. Detailed history taking and examination was done at the time of admission.

\section{Statistical Analysis}

Continuous data were expressed as mean + SD and median and analysed by unpaired ' $\mathrm{t}$ ' test. Categorical data are presented as numbers and percentages were analysed by chisquare test. $P$ value of 0.05 or less was considered as statistically significant.

\section{OBSERVATIONS AND RESULTS}

\begin{tabular}{|c|c|}
\hline & Hypertensive Emergency \\
\hline Mean Age & $63 \pm 10$ \\
\hline Table 1. Mean Age in Patients of Hypertensive Emergency \\
\hline
\end{tabular}

In our study, mean age for hypertensive emergency was $(63 \pm 10)$

\begin{tabular}{|c|c|c|}
\hline Sex & No. of Cases & Percentage (\%) \\
\hline Male & 84 & 58 \\
\hline Female & 60 & 42 \\
\hline Total & $\mathbf{1 4 4}$ & $\mathbf{1 0 0}$ \\
\hline
\end{tabular}

Table 2. Sex Wise Distribution in Patients of Hypertensive Emergency

Out of a total of 144 patients of hypertensive emergencies, 84 patients were males.

\begin{tabular}{|c|c|c|}
\hline Physical Activity & No. of Cases & Percentage (\%) \\
\hline $\begin{array}{c}\text { Sedentary } \\
\text { (light physical activity) }\end{array}$ & 99 & 69 \\
\hline Non-Sedentary & 45 & 31 \\
\hline Total & 144 & 100 \\
\hline $\begin{array}{r}\text { Table 3. Showing } F \\
\text { Hyper }\end{array}$ & $\begin{array}{l}\text { ical Activity } \\
\text { ive Emergen }\end{array}$ & $\begin{array}{l}\text { Patients with } \\
\text { s }\end{array}$ \\
\hline
\end{tabular}

Out of a total of 144 patients of hypertensive emergencies, 99 patients were non-sedentary activity.

\begin{tabular}{|c|c|c|}
\hline Obesity & No. of Patients & Percentage (\%) \\
\hline Obese & 97 & 67 \\
\hline Non-Obese & 47 & 33 \\
\hline Total & $\mathbf{1 4 4}$ & $\mathbf{1 0 0 \%}$ \\
\hline Table 4. Obesity in Patients of Hypertensive Emergencies \\
\hline
\end{tabular}

Out of a total of 144 patients of hypertensive emergencies, 97 patients were obese.

\begin{tabular}{|c|c|c|}
\hline Dyslipidaemia & No. of Patients & Percentage (\%) \\
\hline Dyslipidaemic & 64 & 44 \\
\hline Normal Lipids & 80 & 56 \\
\hline Total & 144 & $100 \%$ \\
\hline \multicolumn{3}{|c|}{$\begin{array}{l}\text { Table 5. Dyslipidaemia in Patients of Hypertensive } \\
\text { Emergencies }\end{array}$} \\
\hline
\end{tabular}

Out of a total of 144 patients of hypertensive emergencies, 64 patients were dyslipidaemic.

\begin{tabular}{|c|c|c|}
\hline Alcohol Intake & No. of Patients & Percentage (\%) \\
\hline Alcoholic & 68 & 47 \\
\hline Non-Alcoholic & 76 & 53 \\
\hline Total & 144 & $100 \%$ \\
\hline
\end{tabular}

Out of a total of 144 patients of hypertensive emergencies, 68 patients were alcoholic.

\begin{tabular}{|c|c|c|}
\hline & No. of Patients & Percentage (\%) \\
\hline Smokers & 62 & 43 \\
\hline Non-Smokers & 82 & 57 \\
\hline Total & 144 & $100 \%$ \\
\hline
\end{tabular}

Out of a total of 144 patients of hypertensive emergencies, 62 patients were smoker.

\begin{tabular}{|c|c|}
\hline Blood Pressure & Hypertensive Emergency \\
\hline SBP & $202 \pm 13$ \\
\hline DBP & $130 \pm 7$ \\
\hline Table 8. Blood Pressure in Patients of Hypertensive \\
Emergency
\end{tabular}

The mean systolic blood pressure of our 144 patients presenting as Hypertensive Emergency was (202 \pm 13 ) and mean diastolic blood pressure of 144 patients presenting as Hypertensive Emergency was (130 \pm 7$)$.

\begin{tabular}{|c|c|}
\hline Target Organ Damage Type & No. of Cases (\%) (n = 144) \\
\hline Retinopathy & 91.67 \\
\hline Cerebral Infarction & 26.39 \\
\hline Intracerebral Haemorrhage & 22.22 \\
\hline Acute Heart Failure & 25 \\
\hline Acute Coronary Syndrome & 22.22 \\
\hline $\begin{array}{c}\text { Transient Ischaemic Attack } \\
\text { (TIA) }\end{array}$ & 5.56 \\
\hline Subarachnoid Haemorrhage & 1.3 \\
\hline Hypertensive Encephalopathy & 1.3 \\
\hline Table 9. Target Organ Damage in Hypertensive Emergency \\
\hline
\end{tabular}

Out of total 144 patients of hypertensive emergency, retinopathy was found in 132 patients (91.66\%), while 82 patients $(57 \%)$ had Central Nervous System involvement with 38 patients $(26.39 \%)$ of cerebral infarction, 32 patients (22.22\%) of intracerebral haemorrhage, 8 patients $(5.56 \%)$ of transient ischaemic attack and 2 patients (1.3\%) of subarachnoid haemorrhage and hypertensive 
encephalopathy each. Among cardiac involvement, 36 patients (25\%) had acute heart failure and 32 patients $(22.22 \%)$ had acute coronary syndrome.

\section{DISCUSSION}

The present study was carried out in patients admitted in Department of Medicine, S. S. Medical College and Associated S. G. M. H, Rewa (M. P.) from March 2015 to May 2016. During this study period, 144 patients of hypertensive emergency who were admitted to the ICU of our Tertiary Care Centre were studied.

In this study, out of 144 patients, 84 patients (58\%) were males and 60 patients (42\%) were females with a Male: Female ratio of 1.4: 1, while in study done by Pacheco et al $(2013)^{4}$ it was $57.8 \%$ to $42.2 \%$ and Male: Female ratio of was 1.37: 1 and in study done by Martin et al (2004) 55.3\% male affected with a Male: Female ratio of 1.24: 1. Male preponderance in our country in hypertensive emergencies can be attributed to the educational and psychological stress. Males are also more likely to approach healthcare setup in our country as compared to females.

In the present study, it was observed that $(69 \%)$ were sedentary workers. Martin et al $(2010)^{6}$ reported that patients with hypertensive emergencies were more sedentary as compared to patients with hypertensive urgencies.

In our study $(67 \%)$ patients were obese, whereas Martin et al $(2010)^{6}$ found no difference with respect to obesity between patients of hypertensive emergencies and urgencies and Saguner et al (2010) ${ }^{7}$ in their study of risk factors in hypertensive crises have reported obesity as a risk factor that was significantly associated with hypertensive crisis.

We observed that (44\%) patients with hypertensive emergencies were dyslipidaemic and Pacheco et al (2013) ${ }^{4}$ reported that increased serum cholesterol was associated with increased incidence of target organ damage. In another study of Guo et al (2009),8 dyslipidaemia was an independent risk factor in patients of hypertension.

In our study, (47\%) patients consumed alcohol and Husain et al $(2014)^{9}$ reported that chronic ethanol consumption (more than three drinks per day, $30 \mathrm{~g}$ ethanol) is associated with an increased incidence of hypertension, while another study done by Puddey et al (2006) ${ }^{10}$ showed that the regular consumption of alcohol elevates blood pressure with global estimates that the attributable risk for hypertensive disease from alcohol is $16 \%$.

In our study, (43\%) patients were smokers. In study done by Pacheco et al (2013) $19.2 \%$ of them were smokers and in study of J F Martin et al (2004) $23.7 \%$ of the patients who presented with hypertensive emergencies were smokers.

The mean systolic blood pressure of our 50 patients presenting as hypertensive emergencies was $(202+/-13)$ $\mathrm{mmHg}$ and the mean diastolic blood pressure of our 144 patients presenting as hypertensive emergencies was (130 +/- 7) mmHg. Study of Pacheco et al (2013) ${ }^{4}$ reported a mean systolic blood pressure of $(210+/-23 \mathrm{mmHg})$, a mean diastolic blood pressure of $(130+/-15 \mathrm{mmHg})$, whereas Zampaglione et al (1996) ${ }^{11}$ reported a mean systolic blood pressure of $(210+/-32 \mathrm{mmHg})$, a mean diastolic blood pressure of $(130+/-15 \mathrm{mmHg})$.

In our study, commonest presentation was cerebral infarction (26.39\%) followed by intracerebral haemorrhage $(22.22 \%)$, while among cardiac involvement 36 patients (25\%) had acute heart failure and 32 patients $(22.22 \%)$ had acute coronary syndrome. Similar findings were observed in study of Martin et al (2004) $)^{5}$ and Martin et al $(2010)^{6}$ in which stroke was most common followed by acute heart failure, whereas in study of Zampaglione et al (1996) ${ }^{11}$ commonest presentation was acute heart failure followed by stroke and our study shows higher proportion of patients with strokes than older studies.

\section{CONCLUSION}

- Retinopathy and CNS manifestations were most commonly encountered end-organ damage in patients of hypertensive emergency.

- We found that patients who presents with one of the target organ damage on further evaluation end up having multiple target organ damage.

- The early detection of multiple target organ damage and appropriate treatment are key determinants for reducing morbidity and mortality among patients of hypertensive emergency.

\section{REFERENCES}

[1] Kearney PM, Whelton M, Reynolds K, et al. Global burden of hypertension: analysis of worldwide data. Lancet 2005;365(9455):217-23.

[2] Ezzati M, Lopez AD, Rodgers A, et al. Selected major risk factors and global and regional burden of disease. Lancet 2002;360(9343):1347-60.

[3] Chobanian AV, Bakris GL, Black HR, et al. Seventh report of the joint national committee on prevention, detection, evaluation, and treatment of high blood pressure. Hypertension 2003;42:1206-52.

[4] Pacheco HG, Victorino NM, Urquiza JP, et al. Patients with hypertensive crises who are admitted to a coronary care unit: clinical characteristics and outcomes. The Journal of Clinical Hypertension 2013;15(3):210-4.

[5] Martin JF, Higashiama E, Garcia E, et al. Hypertensive crisis profile. Prevalence and clinical presentation. Arq Bras Cardiol 2004;83(2):131-6.

[6] Vilela-Martin JF, Vaz-de-Melo RO, Kuniyoshi CH, et al. Hypertensive crisis: clinical-epidemiological profile. Hypertension Research 2011;34(3):367-71.

[7] Saguner AM, Dur S, Perrig M, et al. Risk factors promoting hypertensive crises: evidence from a longitudinal study. Am J Hypertens 2010;23(7):77580.

[8] Guo ZR, Hu XS, Wu M, et al. A prospective study on the association between dyslipidemia and hypertension. Zhonghua Liu Xing Bing Xue Za Zhi 2009;30(6):554-8.

[9] Husain K, Ansari RA, Ferder L. Alcohol-induced hypertension: mechanism and prevention. World J Cardiol 2014;6(5):245.

[10] Puddey IB, Beilin LJ. Alcohol is bad for blood pressure. Clin Exp Pharmacol Physiol 2006;33(9):847-52.

[11] Zampaglione B, Pascale C, Marchisio $M$, et al. Hypertensive urgencies and emergencies. Prevalence and clinical presentation. Hypertension 1996;27(1):144-7. 